\title{
Undergraduate paramedic students' attitudes to e-learning: findings from five university programs
}

\author{
Brett Williams*, Malcolm Boyle, Andrew Molloy, Richard Brightwell, \\ Graham Munro, Melinda Service and Ted Brown \\ Monash University, Frankston, Victoria, Australia \\ (Received 27 January 2011; final version received 28 April 2011)
}

\begin{abstract}
Computers and computer-assisted instruction are being used with increasing frequency in the area of undergraduate paramedic education. Paramedic students' attitudes towards the use of e-learning technology and computer-assisted instruction have received limited attention in the empirical literature to date. The objective of this study was to determine paramedic students' attitudes towards e-learning. A cross-sectional methodology was used in the form of a paperbased survey to elicit students' attitudes to e-learning using three standardised scales. Convenience sampling was used to sample a cross-section of paramedic students at five universities during semester 1 of 2009. The scales used were: the Computer Attitude Survey (CAS), the Online Learning Environment Survey (OLES), and the Attitude Toward CAI Semantic Differential Scale (ATCAISDS). There were 339 students who participated. Approximately onehalf $(57.7 \%)$ were female and most $(76.0 \%)$ were under 24 years of age. Moderate results were noted for the CAS general and education subscales. The CAS results were broadly corroborated by the OLES, although a statistically significant difference between participants preferred and actual results on the OLES Computer Usage subscale identified that participants would prefer to use computers less than they actually do. Similarly, the ATCAISDS found participants were largely ambivalent towards computers. As paramedic degree programs continue to emerge and develop, careful consideration should be given to the usability and utility of various e-learning approaches.
\end{abstract}

Keywords: e-learning; paramedic; higher education

\section{Introduction}

Paramedic education and training in Australia and New Zealand has undergone significant change over the past decade, moving from its former vocational roots to tertiary-level education. Although the first university-based paramedic bachelor degree course began over 10 years ago in Australia, the past five years have seen the number of universities offering paramedic programs increase dramatically. Presently, there are 14 higher education institutions offering either undergraduate or postgraduate entry-level courses. While each of these programs is on-campus, all of these programs still integrate some form of e-learning into their pedagogy. For example, this might include whole units of study delivered via online only, such as clinical fieldwork rotations, or simply elements of blended learning spread

\footnotetext{
*Corresponding author. Email: brett.williams@monash.edu
} 
throughout programs, using programs such as Blackboard or Moodle. Specific elearning examples include sophisticated online virtual patient simulations, formative online quizzes and self-evaluation, and problem-based learning provided via online modules. Although this transition to university-based education has been an important part of the professionalisation of the paramedic discipline, the rate at which these programs have been established has led to the existence of a level of uncertainty about general e-learning teaching approaches or students' perceptions and attitudes to e-learning.

Computers, computer-assisted instruction (CAI) and e-learning are being used with increasing frequency in the area of undergraduate and postgraduate paramedic education. e-Learning refers to Internet-based technologies that are used to enhance teaching (Ruiz, Mintzer, and Leipzig 2006). CAI does not necessarily use the Internet, but typically incorporates audio, multimedia, and student interaction (Rouse 2007). As the Internet is increasingly used to integrate CAI initiatives, the terms e-learning and CAI are becoming synonymous (Ruiz, Mintzer, and Leipzig 2006).

Examples of CAI include initiatives such as DVDs and simulators that allow paramedic students to witness and discuss a range of authentic scenarios, ensuring students experience a breadth of scenarios during their coursework and while on clinical placement to assist them towards work readiness (Williams, Brown, and Archer 2009; Taber 2008). More generally, e-learning can potentially help encourage students' critical thinking, self-reflection, multiculturalism, team work and interprofessionalism (Harden 2008). When e-learning strategies are implemented, the role of the learner often changes from a passive one to one who is self-directed and takes responsibility for their own learning (Williams 2006), indicating that the role of the educator must change to support student's learning.

The integration and use of educational technology and e-learning strategies are being utilised with increasing frequency in the higher education sector. While this integration is simply to avoid falling behind in a world where computers have become ubiquitous; the implementation of such teaching methods should be carefully considered (Govindasamy 2002). Too often e-learning initiatives are seen as a pedagogical panacea in higher education. Moreover, these initiatives are often not based on educational theory, leading to unsuccessful, unrewarding and uninspiring experiences for students and educators alike (Harden 2008). When e-learning strategies and other educational technologies (i.e. Wikis, audience response systems) are used appropriately, it is argued these tools offer better experiential learning and greater student empowerment, which is particularly important given the emergence of the 'Net Generation' (Maag 2006).

Initiatives that involve e-learning must meet the needs of students. e-Learning must contribute to students learning by providing appropriate content, but to be truly effective it must be tailored to students' prevailing attitudes and expectations. The student must be the focus, not the technology (Roe, Carley, and Sherratt 2010).

Attitudes towards computers have changed significantly over the past two decades as computers have become omnipresent; for instance, there is no longer a difference between genders in general attitudes towards computers (Popovich et al. 2008). The major factor affecting attitudes today is anxiety; with there being a negative relationship between anxiety about computer and attitudes towards computers (Popovich et al. 2008; Hegney et al. 2006; Webster et al. 2003). In other words, 
e-learning needs to be appropriate for students' level of ability with computers and using technology, otherwise it will be frustrating (Link and Marz 2006).

Understanding students' attitudes towards e-learning facilitates the development of appropriate educational initiatives. Paramedic students' attitudes towards the use of e-learning technology and CAI have received limited attention in the research literature to date. As such, the objective of this study was to determine paramedic students' attitudes towards e-learning. To do so, a survey of undergraduate students enrolled in paramedic degrees across Australia and New Zealand was conducted using three standardised self-report scales.

\section{Method \\ Design}

A cross-sectional methodology using a paper-based questionnaire encompassing three standardised scales and a demographic section.

\section{Population}

A cross-section of students enrolled in emergency health (paramedic) undergraduate degrees from five universities across Australia and New Zealand during semester 1 of 2009 was surveyed. A convenience sample of students from Monash University (MU), Auckland University of Technology (AUT), Charles Sturt University (CSU), Edith Cowan University (ECU) and Queensland University of Technology (QUT) was used.

\section{Instrumentation}

The Computer Attitude Survey (CAS) is designed to assess participants' attitudes towards computers (Startsman and Robinson 1972). The scale consists of 26 items, each rated on a five-point scale $(1=$ strongly agree, $5=$ strongly disagree). Negative worded items are reversed before undertaking analyses. The first 16 items make up a subscale concerning attitudes towards computers in general (CASg). The remaining 10 items concern attitudes towards computers in education (CASe). Low scores for both sub-scales are indicative of a positive response towards computers. The CAS has previously demonstrated reliability and validity (Wagman 1983; Startsman and Robinson 1972; Steele et al. 2002).

The Online Learning Environment Survey (OLES) is a test that assesses participants' actual and preferred experience with components of an online learning module they have recently completed (Pearson and Trinidad 2005). The scale consists of 54 items rated on five-point scales $(1=$ almost never, $2=$ seldom, $3=$ sometimes, $4=$ often, $5=$ almost always). From the items nine scales are derived, which are outlined in Table 1. Internal consistency has been reported by Trinidad, Aldridge, and Fraser (2004) as ranging from 0.86 to 0.96 . Content validity and face validity were established through a detailed literature review and input from content knowledge experts. Construct validity was established through a factor analysis (Pearson and Trinidad 2005).

The Attitude Towards CAI Semantic Differential Scale (ATCAISDS) is a scale used to elicit participants' attitudes towards the use of computers (Allen 1986). On 
Table 1. Descriptions and examples of the nine OLES subscales.

\begin{tabular}{|c|c|c|c|}
\hline Subscale & $\begin{array}{l}\text { Number } \\
\text { of items }\end{array}$ & Description & Sample item \\
\hline Computer Usage & 6 & $\begin{array}{l}\text { The extent to which students } \\
\text { use their computers as a tool to } \\
\text { communicate with others and to } \\
\text { access information }\end{array}$ & $\begin{array}{l}\text { "I use the computer to } \\
\text { ask the teacher } \\
\text { questions" }\end{array}$ \\
\hline Teacher Support & 8 & $\begin{array}{l}\text { The extent to which the teacher } \\
\text { helps, befriends, trusts and is } \\
\text { interested in students }\end{array}$ & $\begin{array}{l}\text { "The teacher gives me } \\
\text { valuable feedback on } \\
\text { my assignments" }\end{array}$ \\
\hline $\begin{array}{l}\text { Student Interaction } \\
\text { and Collaboration }\end{array}$ & 6 & $\begin{array}{l}\text { The extent to which students } \\
\text { have opportunities to interact } \\
\text { with one another, exchange } \\
\text { information and engage in } \\
\text { collaboration }\end{array}$ & $\begin{array}{l}\text { "I share information } \\
\text { with other students" }\end{array}$ \\
\hline Personal Relevance & 5 & $\begin{array}{l}\text { The extent to which there is a } \\
\text { connection between students' } \\
\text { out-of-school experiences }\end{array}$ & $\begin{array}{l}\text { "I can relate what I } \\
\text { learn to my life } \\
\text { outside of this class" }\end{array}$ \\
\hline Authentic Learning & 5 & $\begin{array}{l}\text { The extent to which students } \\
\text { have the opportunity to solve } \\
\text { real-world problems that are } \\
\text { authentic }\end{array}$ & $\begin{array}{l}\text { "I work on } \\
\text { assignments that deal } \\
\text { with real-world } \\
\text { information" }\end{array}$ \\
\hline Student Autonomy & 5 & $\begin{array}{l}\text { The extent to which students } \\
\text { have opportunities to initiate } \\
\text { ideas, make their own learning } \\
\text { decisions, and the locus of } \\
\text { control is on the student }\end{array}$ & $\begin{array}{l}\text { "I make decisions } \\
\text { about my learning", }\end{array}$ \\
\hline Equity & 7 & $\begin{array}{l}\text { The extent to which students } \\
\text { are treated equally by the } \\
\text { teacher }\end{array}$ & $\begin{array}{l}\text { "I am treated the same } \\
\text { as other students in } \\
\text { this class" }\end{array}$ \\
\hline Enjoyment & 6 & $\begin{array}{l}\text { The extent to which students } \\
\text { are satisfied with their } \\
\text { e-learning environment }\end{array}$ & $\begin{array}{l}\text { "I would enjoy my } \\
\text { education if more of } \\
\text { my classes were } \\
\text { online" }\end{array}$ \\
\hline Asynchronicity & 6 & $\begin{array}{l}\text { The extent to which the } \\
\text { discussion forum promotes } \\
\text { reflective thinking and the } \\
\text { posting of messages at times } \\
\text { convenient to the students }\end{array}$ & $\begin{array}{l}\text { "I read the posted } \\
\text { messages at times that } \\
\text { are convenient to me" }\end{array}$ \\
\hline
\end{tabular}

seven-point scales, participants are asked to select which word they err towards on 14 differential descriptive terms (e.g. rigid or flexible, stimulating or boring). The content validity, factor structure and internal consistency of the ATCAISDS have all been reported as satisfactory (Allen 1986; Brudenell and Carpenter 1990).

\section{Procedures}

At the conclusion of lectures for each year level of each of the universities, students were invited to participate in this study on a voluntary basis. Students were provided with an explanatory statement and were informed that participation was voluntary and anonymous. A non-teaching member of staff facilitated the administration of the questionnaire containing the CAS, OLES, ATCAISDS, and 
demographic questions, and arranged for collection of the completed questionnaires. The questionnaires took approximately 20 minutes to complete and consent on the part of the students was implied by completion and submission of the questionnaire. Ethics approval was obtained from each of the five participating universities' Human Ethics Committees.

\section{Data analysis}

The Statistical Package for Social Sciences (SPSS, version 18.0) was used for data storage, tabulation, and the generation of descriptive statistics. Means were used to describe the descriptive data and the analysis of variance with Tukey Honestly Significant Difference (HSD) post hoc test was used to determine the relationship between the three scales and each university. All tests were two-tailed unless otherwise stated, and results are considered statistically significant if $p<$ 0.05 .

\section{Results}

\section{Demographics}

A total of 339 students participated in this study from five different universities in Australia and New Zealand. The two universities with the largest representation in the sample were MU $(n=116)$ and QUT $(n=116)$. Slightly more than one-half $(57.7 \%)$ of the participants were female and the majority were under 24 years of age $(76.1 \%)$. There was a representation of students from each year of the respective universities' courses; however, first-year and second-year students had the largest representation in the sample. The complete demographic profile of the participants is presented in Table 2 .

\section{Computers}

Participants were asked a number of preliminary questions related to the use of and access to computers. The overwhelming majority owned a computer (94\%), and had unlimited access to both a computer (97.1\%) and the Internet $(97.1 \%)$. The computers that participants have access were mostly new $(<1$ year, $17.4 \% ; 1-2$ years, 47.8\%). When asked whether they had plans to purchase a new computer, most either had no plans $(48.7 \%)$ or indicated they possibly would 18 months into the future $(32.0 \%)$. That is, one-third had an intention to upgrade their computer sometime into the future. Thus computers are accessible by effectively all the students sampled. Indeed, approximately three-quarters $(72.1 \%)$ of the participants reported over $60 \%$ or more of their academic work already involves the use computers in some capacity.

\section{Computer Attitude Survey}

The CASg subscale has a range from 16 to 80 . The participants overall reported an attitude almost exactly in the middle between positive and negative (mean $=49.2$, standard deviation $[\mathrm{SD}]=4.9$ ). The CASe subscale has a range of 10 to 50. Participants' attitude towards the use computers in education was also in the middle between positive and negative (mean $=31.0, \mathrm{SD}=5.2$ ). 
Table 2. Participant profile.

\begin{tabular}{|c|c|c|}
\hline & Number & Percentage \\
\hline \multicolumn{3}{|l|}{ University } \\
\hline Monash University & 116 & 34.2 \\
\hline Auckland University of Technology & 35 & 10.3 \\
\hline Charles Sturt University & 49 & 14.5 \\
\hline Edith Cowan University & 23 & 6.8 \\
\hline Queensland University of Technology & 116 & 34.2 \\
\hline Total & 339 & 100 \\
\hline \multicolumn{3}{|l|}{ Year } \\
\hline First year & 117 & 34.5 \\
\hline Second year & 116 & 34.2 \\
\hline Third year & 12 & 3.5 \\
\hline First-year double degree & 66 & 19.5 \\
\hline Second-year double degree & 12 & 3.5 \\
\hline Third-year double degree & 5 & 1.5 \\
\hline Fourth-year double degree & 10 & 2.9 \\
\hline Not stated & 1 & 0.3 \\
\hline Total & 339 & 100 \\
\hline \multicolumn{3}{|l|}{ Age } \\
\hline $15-19$ years & 132 & 38.9 \\
\hline $20-24$ years & 125 & 36.9 \\
\hline $25-29$ years & 26 & 7.7 \\
\hline $30-34$ years & 28 & 8.3 \\
\hline $35-39$ years & 10 & 2.9 \\
\hline $40-44$ years & 12 & 3.5 \\
\hline $44-49$ years & 4 & 1.2 \\
\hline$>50$ years & 1 & 0.3 \\
\hline Not stated & 1 & 0.3 \\
\hline Total & 339 & 100 \\
\hline \multicolumn{3}{|l|}{ Gender } \\
\hline Female & 195 & 57.5 \\
\hline Male & 143 & 42.2 \\
\hline Not stated & 1 & 0.3 \\
\hline Total & 339 & 100 \\
\hline
\end{tabular}

A statistically significant difference between participants from the different universities and their general attitude towards computers was found, $F(4,311)=40.4$, $p<0.0001$. A post hoc analysis using Tukey HSD found the mean scores for participants from ECU $($ mean $=44.7, \mathrm{SD}=3.0)$ and QUT $($ mean $=45.7, \mathrm{SD}=4.4)$ were significantly lower (better attitude) than the other three universities. An $\eta^{2}$ value of 0.34 suggests the effect size is large.

An analysis of variance also found a statistically significant difference between the participants from the different universities in the attitude toward computers in education, $F(4,314)=21.6, p<0.0001$. A post hoc analysis using Tukey HSD again found ECU and QUT to have statistically significantly higher means (worse attitude) than the participants from the other three universities. The effect size for the difference between participants, using $\eta^{2}$, was large at 0.22 . The mean scores for both the CASg and CASe subscales are presented in Table 3. 
Table 3. Computer Attitudes Survey results.

\begin{tabular}{|c|c|c|c|c|}
\hline \multirow[b]{2}{*}{ University } & \multicolumn{2}{|c|}{ General (CASg) } & \multicolumn{2}{|c|}{ Education (CASe) } \\
\hline & Mean & $\mathrm{SD}$ & $\overline{\text { Mean }}$ & $\overline{\mathrm{SD}}$ \\
\hline Monash University & 51.4 & 4.2 & 28.9 & 5.2 \\
\hline Auckland University of Technology & 50.7 & 3.6 & 28.5 & 4.3 \\
\hline Charles Sturt University & 52.0 & 2.9 & 29.8 & 4.6 \\
\hline Edith Cowan University & 44.7 & 3.0 & 33.2 & 3.0 \\
\hline Queensland University of Technology & 45.8 & 4.4 & 34.0 & 4.3 \\
\hline Overall & 49.2 & 4.9 & 31.0 & 5.2 \\
\hline
\end{tabular}

Note: possible scores range from 16 to 80 for General and 10 to 50 for Education

\section{Online Learning Environment Survey}

The overall results for the OLES are presented in Table 4. Paired-sample $t$ tests found statistically significant differences between the actual and preferred results for the Computer Usage, Personal Relevance, Authentic Learning, and Asynchronicity subscales. The $\eta^{2}$ statistic, however, shows that the magnitude of the difference between participants' actual and preferred results was only large for the Computer Usage subscale. On this subscale, participants overall indicated that they would prefer slightly less use of computers in their university education.

A statistically significant difference was found between participants from the different universities and their actual and preferred mean scores for the nine subscales. These results are presented in Table 5.

The two subscales with the largest magnitude of difference between the mean scores reported by participants from different universities, as measured by $\eta^{2}$, was preferred Teacher Support $\left(\eta^{2}=0.45\right)$ and preferred Student Autonomy $\left(\eta^{2}=0.26\right)$.

For Teacher Support, participants from ECU (mean $=17.4, \mathrm{SD}=4.4)$ would prefer more teacher support than those participants from MU, AUT and CSU. The participants from QUT would prefer even more, again (mean $=20.6$, SD $=5.5$ ). It is of note that a statistically significant difference was noted between the actual Tea-

Table 4. Overall participant actual and preferred for OLES subscales.

\begin{tabular}{|c|c|c|c|c|c|c|}
\hline \multirow[b]{2}{*}{ Subscale } & \multicolumn{2}{|c|}{ Actual } & \multicolumn{2}{|c|}{ Preferred } & \multirow[b]{2}{*}{$p$ value } & \multirow[b]{2}{*}{$\eta^{2}$} \\
\hline & Mean & $\mathrm{SD}$ & Mean & $\mathrm{SD}$ & & \\
\hline Computer Usage & 15.2 & 3.8 & 13.2 & 3.8 & 0.000 & 0.24 \\
\hline Teacher Support & 16.1 & 5.6 & 15.3 & 6.1 & 0.104 & 0.01 \\
\hline Student Interaction and Collaboration & 11.4 & 4.6 & 11.2 & 4.2 & 0.285 & 0.00 \\
\hline Personal Relevance & 10.0 & 3.6 & 9.5 & 3.3 & 0.013 & 0.02 \\
\hline Authentic Learning & 9.7 & 3.4 & 9.0 & 3.3 & 0.000 & 0.04 \\
\hline Student Autonomy & 8.8 & 3.1 & 8.4 & 3.2 & 0.078 & 0.01 \\
\hline Equity & 11.0 & 4.3 & 10.7 & 4.1 & 0.114 & 0.01 \\
\hline Enjoyment & 15.4 & 5.0 & 15.2 & 5.0 & 0.130 & 0.01 \\
\hline Asynchronicity & 17.3 & 6.0 & 16.6 & 6.6 & 0.002 & 0.03 \\
\hline
\end{tabular}

Note: Paired-sample $t$ test used to determine statistical significance. 
Table 5. OLES subscales tabulated against universities.

\begin{tabular}{|c|c|c|c|c|c|c|c|c|c|}
\hline \multirow[b]{2}{*}{ Computer Usage } & \multirow[b]{2}{*}{ Actual } & \multicolumn{5}{|c|}{ Mean scores } & \multirow{2}{*}{$\begin{array}{c}\text { Overall } \\
15.2\end{array}$} & \multirow{2}{*}{$\frac{p \text { value }}{0.000}$} & \multirow{2}{*}{$\frac{\eta^{2}}{0.06}$} \\
\hline & & 15.2 & 13.2 & 17.0 & 14.7 & 15.1 & & & \\
\hline & Preferred & 13.5 & 12.5 & 14.0 & 11.4 & 13.2 & 13.2 & 0.053 & 0.03 \\
\hline \multirow{2}{*}{ Teacher Support } & Actual & 18.3 & 17.9 & 16.9 & 12.8 & 13.4 & 16.1 & 0.000 & 0.17 \\
\hline & Preferred & 12.6 & 11.6 & 11.0 & 17.4 & 20.6 & 15.3 & 0.000 & 0.45 \\
\hline \multirow{2}{*}{$\begin{array}{l}\text { Student Interaction and } \\
\text { Collaboration }\end{array}$} & Actual & 12.7 & 14.1 & 12.4 & 9.3 & 9.2 & 11.4 & 0.000 & 0.16 \\
\hline & Preferred & 10.5 & 11.3 & 10.0 & 12.7 & 12.0 & 11.2 & 0.005 & 0.04 \\
\hline \multirow[t]{2}{*}{ Personal Relevance } & Actual & 10.6 & 11.9 & 11.3 & 9.1 & 8.3 & 10.0 & 0.000 & 0.15 \\
\hline & Preferred & 8.6 & 9.3 & 9.1 & 11.9 & 10.2 & 9.5 & 0.000 & 0.08 \\
\hline \multirow[t]{2}{*}{ Authentic Learning } & Actual & 11.0 & 10.5 & 10.2 & 9.4 & 8.0 & 9.7 & 0.000 & 0.15 \\
\hline & Preferred & 8.3 & 7.8 & 7.5 & 11.5 & 10.2 & 9.0 & 0.000 & 0.15 \\
\hline \multirow{2}{*}{ Student Autonomy } & Actual & 9.5 & 9.4 & 9.5 & 8.3 & 7.5 & 8.8 & 0.000 & 0.09 \\
\hline & Preferred & 7.4 & 6.7 & 6.9 & 11.1 & 10.2 & 8.4 & 0.000 & 0.26 \\
\hline \multirow[t]{2}{*}{ Equity } & Actual & 11.3 & 12.8 & 12.1 & 10.0 & 9.9 & 11.0 & 0.001 & 0.06 \\
\hline & Preferred & 9.7 & 9.0 & 9.7 & 11.2 & 12.4 & 10.7 & 0.000 & 0.10 \\
\hline \multirow[t]{2}{*}{ Enjoyment } & Actual & 15.6 & 16.3 & 17.4 & 12.8 & 14.6 & 15.4 & 0.001 & 0.06 \\
\hline & Preferred & 14.6 & 13.6 & 15.6 & 14.9 & 16.1 & 15.2 & 0.065 & 0.03 \\
\hline \multirow{2}{*}{ Asynchronicity } & Actual & 17.2 & 15.8 & 16.9 & 16.9 & 18.2 & 17.3 & 0.332 & 0.01 \\
\hline & Preferred & 14.7 & 13.7 & 14.2 & 18.3 & 20.4 & 16.6 & 0.000 & 0.18 \\
\hline
\end{tabular}

cher Support for participants from each university, with participants from ECU and QUT reporting lower mean scores, indicative of less teacher support (Table 5).

With regard to Student Autonomy, participants from ECU (mean $=11.13, \mathrm{SD}=$ 3.0) and QUT (mean $=10.2, \mathrm{SD}=3.4$ ) reported that they would prefer significantly more autonomy than the other three universities. It is of note that there was a statistically significant difference in the actual Student Autonomy means by university. Participants from ECU reported a lower mean score for actual Student Autonomy, although not by a statistically significant margin. Participants from QUT, however, reported a statistically significant lower mean score for actual Student Autonomy (Table 5).

\section{Attitude towards the CAI semantic differential scale}

Overall the participants' mean responses were close to the midpoint of four for each semantic differential item. There was, however, one standout differential scale item rating; participants erred toward the term 'Personal', as opposed to computers being 'Impersonal'. The overall results are presented in Table 6.

Comparing the responses of participants from different universities with the 14 semantic differential rating items found statistically significant differences for all but the last differential scale item, 'Time saving-Time consuming'; for this differential rating item, participants from all five universities overall erred to a small degree toward computers being 'Time saving' (see Table 6).

Post hoc analyses found that in most cases it was participants from ECU or QUT whose opinions on the semantic differential scale items that differed. In most cases, participants from ECU and QUT reported more negative attitudes towards computers, with the most striking differences being their perception of computers as more inefficient, whereas participants from the other three universities viewed 
Table 6. Semantic differential differences between participants from different universities.

\begin{tabular}{lccccccc}
\hline Semantic differential & \multicolumn{4}{c}{ Mean scores } & & Overall & $p$ value \\
\hline $1=$ rigid, 7 = flexible & 4.10 & 4.06 & 4.55 & 2.87 & 2.42 & 3.53 & 0.000 \\
$1=$ useful, 7 = useless & 2.64 & 2.71 & 2.76 & 3.45 & 4.11 & 3.18 & 0.000 \\
$1=$ stimulating, 7 = boring & 3.71 & 3.97 & 4.12 & 2.23 & 2.96 & 3.46 & 0.000 \\
$1=$ meaningless, 7 = meaningful & 3.09 & 2.85 & 3.94 & 4.05 & 4.24 & 3.62 & 0.000 \\
$1=$ pleasant, 7 = unpleasant & 3.49 & 3.50 & 3.92 & 2.82 & 3.76 & 3.60 & 0.016 \\
$1=$ valuable, 7 = worthless & 2.83 & 2.79 & 2.88 & 3.45 & 3.87 & 3.20 & 0.000 \\
$1=$ creative, 7 = unimaginative & 3.75 & 3.62 & 3.80 & 2.32 & 3.13 & 3.45 & 0.000 \\
$1=$ impersonal, 7 = personal & 5.41 & 4.88 & 5.88 & 4.27 & 4.25 & 4.99 & 0.000 \\
$1=$ efficient, 7 = inefficient & 2.65 & 2.59 & 2.65 & 5.86 & 5.18 & 3.65 & 0.000 \\
$1=$ inappropriate, 7 = appropriate & 3.24 & 3.21 & 3.14 & 2.32 & 3.11 & 3.12 & 0.045 \\
$1=$ comfortable, 7 = uncomfortable & 3.08 & 3.03 & 3.24 & 2.77 & 3.64 & 3.25 & 0.011 \\
$1=$ nonthreatening, 7 = threatening & 2.52 & 2.44 & 2.80 & 2.59 & 3.47 & 2.85 & 0.000 \\
$1=$ overpowering, 7 = easy to control & 3.10 & 2.94 & 3.69 & 2.23 & 3.05 & 3.10 & 0.002 \\
$1=$ time saving, 7 = time consuming & 2.95 & 3.59 & 3.53 & 3.14 & 3.18 & 3.19 & 0.096 \\
\hline
\end{tabular}

computers as more efficient. The mean scores for each semantic differential item, tabulated against the participants' universities are presented in Table 6.

\section{Discussion}

The majority of students in this study have access to, and use, a computer that is connected to the Internet. This is a reflection of the ubiquity of computers and the Internet in today's society. Computers have also become an essential tool in university life with most assignments requiring a computer to be completed. Indeed, the vast majority, if not all, of essays are typed nowadays; many library resources are available online, and in recent times pen-based computers (known as tablets) have been introduced for students to take notes and interact in lectures. Although the integration and utilisation of e-learning is rapidly changing and evolving, as are student expectations, the reality is that, despite the available educational technology, e-learning does not automatically improve teaching and learning. Gaining a better understanding of students' attitudes towards e-learning will provide educators with greater insight and likelihood to develop strategies that match students' needs.

The ubiquity of computers is evident in the CAS results. Participants had moderate views towards computers in general (CASg). No enthusiasm for computers was evident in the results. An analysis of the attitudes towards computers by university found participants from ECU and QUT had significantly better attitudes towards computers in general than participants from the other three universities. The attitudes of participants from ECU and QUT towards computers in education (CASe) were, however, more negative. Overall, participants' attitudes towards computers in education were also moderate. These findings suggest further research should be undertaken. For example, are these results related to units of study that use a blended approach, combining face-to-face with e-learning? Or are e-learning platforms such as Blackboard or Moodle simply used by teaching staff as digital repositories, offering students little engagement or synchronous communication?

The OLES results were similar to the CASg/CASe results; however, caution is advised when interpreting the results of this standardised scale. The first subscale Computer Usage, for instance, does not enquire into all the uses a student may make of a computer. The most noticeable omission is an item concerning the use of 
computers to conduct research for assignments. The scale also enquires into frequency rather than the participants' agreement with items, and in doing so confounds the interpretation of how often something is done irrespective of computers and how often something is done with a computer. How participants are answering is, therefore, not explicitly clear.

The strength of the OLES, however, is the comparison between participants' actual and preferred attitudes and opinions. A number of statistically significant differences were noted; however, only the Computer Usage subscale had a large magnitude of difference. It was noted that participants indicated they would prefer to use computers less than they actually do for university-related work. These findings provide important information for the paramedic discipline, particularly as course accreditation of national programs will soon take place. This will provide curriculum designers with a better insight into ways of improving students' attitudes towards CAI and also develop better pedagogical strategies involving teaching using educational technologies.

An analysis of participants' responses to the OLES by university found two important differences. Participants from ECU and QUT would prefer more teacher support and more student autonomy than the participants from the other three universities. It appears that the participants from ECU and QUT are not as confident with computers as their peers from the other universities. A negative relationship between computer anxiety and attitudes towards computers has been found elsewhere (Popovich et al. 2008). Such an explanation would adequately explain the difference between participants from ECU and QUT and the other three universities.

The findings of the semantic differential scales corroborate the results of the CAS and OLES. Overall the mean score for each differential item was around the midpoint of four, erring towards the more positive word. The only differential item to stand out was the Personal-Impersonal sematic scale, where participants indicated that computers were personal. This perception is an important area for paramedic education and training, particularly as e-learning offers greater scope providing authentic learning activities (e.g. patient scenario software, or virtual learning spaces that are otherwise more difficult to achieve). Thus, if students view computers as personal then this may provide the context for better student engagement, and better intended and observed learning outcomes.

An analysis of the semantic differential scale ratings by university found the differences were predominantly between participants from both ECU and QUT and the other three universities. Consistent with the results of the CAS and OLES, participants from ECU and QUT generally had worse attitudes towards computers, most noticeably in regard to their considering them inefficient. Participants from MU, AUT and CSU considered computers to be efficient. This difference is consistent with the notion that participants from MU, AUT and CSU are more confident in their ability to use computers. There may be some differences in the orientation and training sessions that students are provided with at each of the universities. As well, there may be differences in the number of computers available for student use and the accessibility of computer laboratories to students (e.g., weekends, late at night) at each university. These may be factors that account for part of the difference between AUT and CSU compared with the other three universities.

The sample of paramedic students from across Australia and New Zealand is a strength of this study, despite convenience sampling having been used. It is recommended for future study that efforts to understand the needs and wants of paramedic 
students with regard to computers delve into more specific aspects. There appears to be significant differences between attitudes of students from different universities, although none exhibit unbounded enthusiasm for computers. This would suggest that the manner in which computers are taught, the availability of computers, access to specific computer programs (e.g. the statistical program SPSS) and the use of computers varies with measureable effects on students.

This study is limited in its ability to delve into specifics, and therefore requires further investigation. This sample of paramedic students appears ambivalent towards computers and, as such, efforts to engage them and maximise the utilisation of computers needs to address their concerns and needs. By not doing so, faculties risk spending significant sums of money implementing e-learning initiatives that could potentially go underutilised and offer poor learning opportunities. Consequently, as paramedic-orientated degree programs continue to emerge and develop, careful consideration should be given to the usability, utility, and sustainability of e-learning approaches.

\section{Conclusion}

This study has provided significant foundational data for the Australian and New Zealand paramedic discipline, particularly as the body of knowledge in e-learning pedagogy is limited. Results from this study indicate that paramedic student attitudes towards computers in general and computers in education found participants to have moderate attitudes, but a degree of ambivalence was evident. Consequently these participants did not indicate an interest in computers for computers' sake. With such attitudes, students are unlikely to utilise e-learning initiatives to their maximum unless they meet their needs. As paramedic-orientated degree programmes continue to emerge and develop, careful consideration should be given to the usability and utility of e-learning approaches and overall integration into curriculum.

\section{Acknowledgements}

The authors would like to acknowledge the paramedic students from the participating universities who took part in the study.

\section{References}

Allen, L. 1986. Measuring attitude toward computer assisted instruction: The development of a semantic differential tool. Computers in Nursing 4, no. 4: 144-51.

Brudenell, I., and C.S. Carpenter. 1990. Adult learning styles and attitudes toward computer assisted instruction. The Journal of Nursing Education 29, no. 2: 79-83.

Govindasamy, T. 2002. Successful implementation of e-learning pedagogical consideration. The Internet and Higher Education 4: 287-99.

Harden, R.M. 2008. E-learning - Caged bird or soaring eagle? Medical Teacher 30: 1-4.

Hegney, D., R. Eley, E. Buikstra, T. Fallon, J. Soar, and V. Gilmore. 2006. Australian nurses access and attitudes to information technology - A national survey. Studies in Health Technology and Infomatics 122, no. 6: 88-92.

Link, T.M., and R. Marz. 2006. Computer literacy and attitudes towards e-learning among first year medical students. BMC Medical Education 6, no. 34.

Maag, M. 2006. Podcasting and MP3 players: Emerging education technologies. Computers, Informatics, Nursing 24, no. 1: 9-13. 
Pearson, J., and S. Trinidad. 2005. OLES: An instrument for refining the design of e-learning environments. Journal of Computer Assisted Learning 21, no. 6: 396-404.

Popovich, P.M., N. Gullekson, S. Morris, and B. Morse. 2008. Comparing attitudes towards computer usage by undergraduates from 1986 to 2005. Computers in Human Behavior 24: 986-92.

Roe, D., S. Carley, and C. Sherratt. 2010. Potential and limitations of e-learning in emergency medicine. Emergency Medicine Journal 27: 100-4.

Rouse, D.P. 2007. Computer-assisted instruction: An effective instructional method. Teaching and Learning in Nursing 2: 138-43.

Ruiz, J.G., M.J. Mintzer, and R.M. Leipzig. 2006. The impact of e-learning in medical education. Academic Medicine 81, no. 3: 207-12.

Startsman, T.S., and R.E. Robinson. 1972. The attitudes of medical and paramedical personnel toward computers. Computers in Biomedical Research 5: 218-27.

Steele, D., J. Palensky, T. Lynch, N. Lacy, and S. Duffy. 2002. Learning preferences, computer attitudes, and student evaluation of computerised instruction. Medical Education 36, no. 3: 225-35.

Taber, N. 2008. Emergency response: Elearning for paramedics and firefighters. Simulation \& Gaming 39, no. 4: 515-27.

Trinidad, S., J. Aldridge, and B. Fraser. 2004. Development and use of an online learning environment survey. Paper presented at the annual meeting of the American Educational Research Association AERA, April 12-16, San Diego, CA.

Wagman, M. 1983. A factor analytic study of the psychological implications of the computer for the individual and society. Behavioural Research Methodology and Instrumentation 15: 413-19.

Webster, J., J. Davis, V. Holt, G. Stallan, K. New, and T. Yegdich. 2003. Australian nurses' and midwives' knowledge of computers and their attitudes to using them in their practice. Journal of Advanced Nursing 41, no. 2: 140-6.

Williams, B. 2006. Qualitative analysis of undergraduate paramedic students' perceptions of using case-based learning in an online learning environment. Journal of Emergency Primary Health Care 4, no. 3.

Williams, B., T. Brown, and F. Archer. 2009. Can DVD simulations provide an effective alternative for paramedic clinical placement education? Emergency Medicine Journal 26: $377-81$. 